\title{
Increasing Hispanic Students' Awareness and Use of Floor-robots through Structured Activities
}

\author{
Jane Elizabeth Casey \\ Texas A\&M University Central Texas, USA \\ ORCID: 0000-0002-3331-0879 \\ Lisa K. Pennington \\ Governors State University, USA \\ ORCID: 0000-0002-3599-934X \\ Dallas Lopez \\ Texas A\&M International University, USA \\ ORCID: 0000-0003-4987-836X
}

Received: 8 Feb 2020

Accepted: 27 Jul 2020

\begin{abstract}
When educators provide students with opportunities to interact with educational technology such as floor-robots, it may: (a) increase students' awareness of new educational tools, and (b) enhance students' use and engagement with new technologies. This case study provided upper-elementary, Hispanic students with opportunities to engage in structured and unstructured activities with floor-robots, with direct support from researchers and the cooperating teacher. These educational robots were introduced to student-participants on multiple occasions during regular instructional class time in a Title I school on the U.S.-Mexico border to determine: (a) students' interest in continued use of floor-robots; and (b) students' perceptions of ease-of-use of floor-robots. Floor-robots were selected largely because researchers had access to two types: a Roamer floor-robot and a Thymio floor-robot. For students from underserved populations, it is important that educators strengthen students' self-efficacy in science, technology, engineering, and mathematics (STEM) areas (Mau \& Li, 2018), as well as increase students' awareness and use of newer educational technologies, which is a growing field and includes floor-robots. However, in-service teachers may need guidance, support, and professional development when selecting and using new educational technologies such as floor-robots. Student-participants' post-study surveys and interviews provided researchers with insight into elementary students': (a) interest in floor-robots and robotics, (b) perceived ease-of-use, (c) preferred type of floor-robot in this particular study, and, (d) opinions on the potential uses and downsides of floor-robots.
\end{abstract}

Keywords: Hispanic students, floor-robots, English language learners

\section{INTRODUCTION}

Next Generation Science Standards (NGSS) promote science, technology, engineering and mathematics (STEM) learning for all K-12 learners, but not all schools provide the same level of support in the teaching and learning of science and mathematics (Aschbacher, Li, \& Roth, 2010) or similar access to new educational technologies. Schools with large student-populations from low socio-economic status (SES) backgrounds may not have sufficient funds to allocate toward new and/or innovative educational technology, which limits students' awareness and opportunities. Likewise, Aschbacher et al. (2010) noted that family support in low 
SES homes may be lacking in terms of support for pursuing STEM careers, even for students who desired to follow a STEM career. Compounding the inequity in allocation of funds and lack of family support for various reason, schools serving large populations of students from low SES communities often have a higher percentage of minority students, including Hispanic students. Hispanic students are also more likely to be first-generation college students with limited knowledge in the intricacies involved in pursuing and persisting in a college path (Engle \& Tinto, 2008; Perna, 2015). Many schools serving underserved (i.e., at-risk, minority, English language learner) students continue to be focused on increasing students' academic scores on state mandated tests. Thus, there is a heavy emphasis on testing and less focus on scientific inquiry, which plays out through middle and high school and may lead to a lower self-efficacy in STEM ability (Conley, Pintrich, Vekiri, \& Harrison, 2004). This can impact pursuit of higher education and/or STEM career choices.

\section{Critical Issues in STEM Education}

At the present time, female and minority students are under-represented in STEM career fields for a variety of reasons (Beasley \& Fisher, 2012; Mau \& Li, 2018; Sadler, Sonnert, Hazari, \& Tai, 2012; Seo, Shen, \& Alfaro, 2019). Beasley and Fisher (2012) noted that there are disproportionate numbers of female, Hispanics, and Blacks leaving "STEM majors for which their underrepresentation has at times been attributed to lack of competence in these fields" (p. 444). In this technology laden world, it is important to ensure all students are prepared to pursue a STEM career through appropriate coursework, effective instruction, and other opportunities, such as being introduced to or actively engaging with new technologies. It is imperative to support underserved $\mathrm{K}-12$ students in science through effective instruction, strong content, and access to new technologies to facilitate their background knowledge. It is also important to support K-12 firstgeneration college students, who may lack supports and/or knowledge needed to successfully navigate the intricacies of applying for and persisting to completion of a college degree (Blackwell \& Pinder, 2014; Boden, 2011; Boschma \& Brownstein, 2016; Engle \& Tinto, 2008; Gamez-Vargas \& Oliva, 2013; Perna, 2015; Sparkman, Maulding, \& Roberts, 2012). New forms of technology continue to be developed each year, and millions of people have access to the latest phones, iPads, computers, virtual reality platforms, high-speed internet, social networks, etc. However, underserved students in K-12 schools may lack the same access to the latest technologies as their more affluent counterparts.

\section{Promising Potential Supports}

Introducing students from underserved backgrounds to educational robots may facilitate increased awareness and use of new technologies, and this is especially significant in the elementary years. Students who engage in such activities may also develop a greater awareness of STEM-related career fields. Many researchers have conducted studies to determine the effects of educational robots on K-12 students': (a) creative thinking (Nemiro, Larriva, \& Jawaharlal, 2017), (b) advanced spatial thinking (Francis, Bruce, Davis, Drefs, Hallowell, Hawes, McGarvey, Moss, Mulligan, Okamoto, Sinclair, Whiteley, \& Woolcott, 2017), (c) collaborative abilities (Khanlari, 2016), and, (d) self-efficacy and/or academic ability in STEM (Toh, Causo, Tzuo, Chen, \& Yeo, 2016). Adding to the knowledge base on how educational robots can be used in classrooms is essential. This case study was conducted in a Title I school on the U.S.-Mexico border to determine fifth-grade, Hispanic students' perceptions of floor-robots.

This study builds on findings from a previous study that introduced underserved Hispanic students attending schools on the U.S.-Mexico border to one type of floor-robot (Casey, Gill, Pennington, \& Mireles, 2018). Findings from this grant-funded study provided researchers with insight into Hispanic students' perceptions about the ease-of-use of floor-robots while engaging in structured activities, as well as some benefits/drawbacks of floor-robots.

\section{LITERATURE REVIEW}

There is a limited body of research on floor-robots in elementary schools. In a search of peer-reviewed articles in the ERIC (EBSCO) database using keywords elementary and technology, between the years 2008 to 2018, 8379 articles were retrieved. This search produced a vast array of articles, including: (1) a grounded 
theory study of elementary teacher candidates' use of second life (Bahnga \& Lee, 2017), a virtual reality world; and, (2) enhancing preservice teachers intent to use probeware in elementary classrooms to enhance student learning (Ensign, Rye, \& Luna, 2017). When the keyword floor-robot was added, no articles were retrieved. When the keywords elementary, technology, and robot were used, 50 articles were retrieved; many of those were discarded due to lack of alignment with search criteria. When the same three search terms and publication years were put into the Association of Computing Machinery (ACM) database, 17 articles were retrieved; of those, 16 were published by ACM conference proceedings.

Kanda, Sato, Saiwaki, and Ishigo (2007) introduced Robovie, a robot that the researchers developed, into elementary classrooms to research human-robot social interactions/relationships, specifically communication. Researchers' analysis revealed that "the robot successfully continued interacting with many children for two months, and seemed to have established friendly relationships with them" (Kanda et al., 2007, p. 962). Jeon, Fakhr Hosseini, Barnes, Duford, Zhang, Ryan, and Vasey (2016) introduced floor-robots to rural students, via Robot Theater, to enhance students' writing, with positive results. Khanlari (2016) noted that in-service teachers "agreed that robotics has the potential to improve students' collaboration and teamwork abilities" (p. 328). However, in-service teacher-participants believed that the technology was too costly and "requires extra time to plan learning activities, consumes too much time for training and dealing with technical problems, and increases teachers' workload in the short term" (p. 328). This last finding is significant, as teachers must be properly prepared to effectively use technology for students to receive meaningful benefits.

Toh et al. (2016) conducted a review of the literature with specific criteria in place for inclusion. Four themes emerged that demonstrated student-participants, after engaging with floor-robots, had increased: (a) problem solving and collaboration; (b) academic achievement, science concepts, and sequencing skill development; (c) language development; and (d) participation. Toh et al. concluded that the "use of robots has the potential to help children develop various academic skills like science process understanding, mathematical concept development and improvement of achievement scores" (2016, p. 154).

Francis et al. (2017) collected data on participants' observations after watching a video of students engaged in programming robots. All participants watched the exact same video segments. Francis et al. (2017) noted that across all participants' responses, there was a "dominant observation that both spatial thinking and design thinking were central to the student work" (p. 175). Participants who watched the video had a range of STEM backgrounds, but participants also included architects and artists. Francis et al. (2017) reported that there is limited research on how working with robots can enhance spatial thinking and/or spatial awareness.

Nemiro et al. (2017) collected data on elementary students who were engaged in robotics; as the study continued, researchers noted that students' creative behaviors were enhanced. Creative activities included students' developing designs for robots. Nemiro et al. (2017) noted that the intervention classrooms were often places of chaotic energy and student-directed engagement. However, a major limitation was a lack of formal training. Nemiro et al. (2017) concluded that future implementation and/or studies should include "more formalized creativity training for both the students and the teachers" (p. 89).

Although there is a growing body of research on educational robots in elementary classrooms, it is important to expand the knowledge base. Most studies suggest that students benefit when engaged in new technologies. However, in-service teachers' perceptions on the time, cost, and additional work when using new technologies must be considered and addressed.

\section{METHODS}

Research Design. This case study (Yin, 2013) expands on outcomes from a pilot study that took place in the prior academic year (Casey et al., 2018). With IRB approval, researchers developed assessment measures to gather additional data. A nine-question survey was developed, with specific precautions taken in language usage due to student-participants' age and dominant language identification. Researchers had previously used Likert surveys with elementary students, using explicit instruction, examples, and practice surveys to 


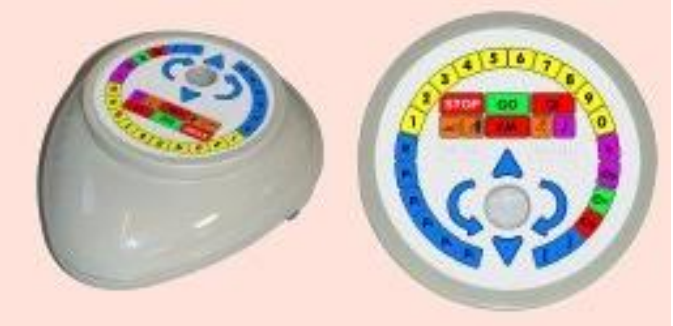

Figure 1. Roamer Floor-robot

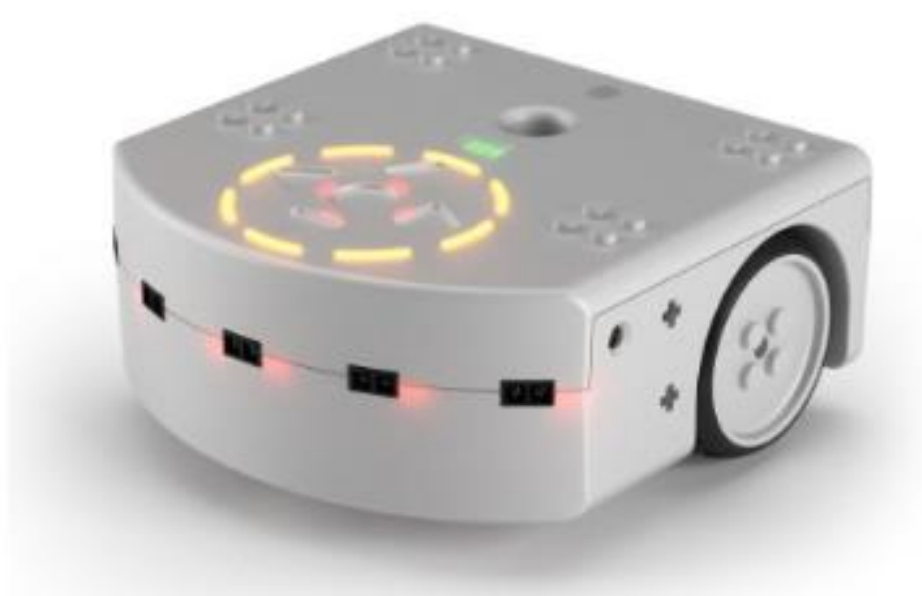

Figure 2. Thymio floor-robot

teach students how to identify and select a response. However, students often struggled with the Likert survey; and in this study, researchers determined that giving elementary student-participants the option, when possible, to answer yes or no, would produce a more accurate response. When developing any Likert survey, researchers "must adequately capture the specific domain of interest yet contain no extraneous content" (Hinkin, 1995, p. 969). Researchers wanted to capture the domain of interest, student-participants' perceptions of floor-robots, in as accurate a fashion as possible. Multiple drafts of the survey were developed prior to finalizing the one used in this study to help ensure content validity. However, the survey was researcher-developed, and as such, reliability had not been established.

In addition to the survey, researchers returned to the school approximately a month after the structured activities and asked student-participants to respond to two questions: (a) If you could create a floor-robot, what would you want it to do? and, (b) What is your favorite thing about these robots? Researchers were interested in students' perceptions about floor-robots, as well as gaining insight into student-participants' thoughts about floor-robots on a broader scale.

During this investigation, researchers conducted a number of structured and unstructured activities in elementary classrooms over the course of multiple months with the Roamer (Figure 1) and Thymio (Figure 2) floor-robots. However, data collection was specific to student-participants' engagement during this one day, which was a culminating event. All activities were structured and developed for use in small groups, and students relied on previous experience with both types of floor-robots, including their knowledge of programming. Researcher-developed activities included: (a) programming the Roamer to draw a square, a triangle, and a rectangle onto large butcher paper; (b) programming the Thymio to draw circles, figure eights, and small to large concentric rings onto paper; and, (c) programming the Roamer to travel through a maze to reach a desired end point. After all student-participants had participated in all activities, they responded to a survey about the activities and the specific floor-robots.

Student-participants. Student-participants attended a Title I school on the U.S.-Mexico border. The population of the city is $96.5 \%$ Hispanic, and student-participants were $100 \%$ Hispanic. The school 
administration continues to develop a plan to improve student learning. Of the 795 students who attend this school, $93.5 \%$ of students are economically disadvantaged, $75 \%$ of students are English language learners (ELLs), and $4.7 \%$ of students have been identified with a disability. English proficiency of students in this study varied, with some students speaking only Spanish, some students speaking primarily English, and the majority of students having varying degrees of bilingualism.

On state assessments across all grade levels and subjects in the prior school year at the participating school, approximately $30 \%$ of students received "Meets Grade Level" performance score and $70 \%$ of students received "Approaches Grade Level". Statewide, only fifth graders take a science assessment; and at the participating school, $61 \%$ scored "Approaches Grade Level", with $28 \%$ of fifth graders receiving "Meets Grade Level". However, that number dropped for females (22\% met) and for ELLs (12\% met).

When looking at the percent of students at "Masters Grade Level" standard, meaning students who were identified as advanced, student data across all grades at the school was weak. The school did not achieve a federal performance target requirement, and this school has not earned any distinctions on testing. This school was selected by researchers specifically to address students' academic needs in science. Studentparticipants took part in a variety of structured and unstructured activities with floor-robots across a 16 week period to support students' awareness of and engagement with new technologies, especially female and minority students. Along with the effects of metacognitive strategy instruction (Casey, 2018) on Hispanic students' comprehension of science content, researchers were specifically interested in determining students' perceptions of floor-robots. All students had opportunities to engage in activities with floor-robots, although only 67 of 92 students had parental permission to respond to a researcher-developed survey.

Intervention. Floor-robots were selected as an appropriate intervention for determining studentparticipants' awareness of new technologies; and the Thymio and Roamer were used because they were available to the researchers. In an initial pilot study in the previous academic year, students engaged with Roamer to become more aware of writing program code (Casey et al., 2018). Similar activities were conducted when students were first introduced to the floor-robots during this case-study. After initial trialand-error, students were provided explicit instruction in programming. Students were asked to have the floor-robot travel in precise geometric patterns, including a square, rectangle, and triangle; and students were also asked to write down a short or long version of program code using symbols on the interface of the Roamer. A typical string of code to have the Roamer travel in a square included: R4 [forward arrow, 2, turn right arrow, 90] go. There was a longer string of code that students learned prior to using the aforementioned code, with R4 standing for repeat four times. After students learned the code, they were asked to insert magic markers into a round hole on the Roamer, and a visual image of a geometric shape was immediately seen on paper taped to the floor. This served to assist students' understanding of the importance of using exact coding. All programming was done by students touching specific buttons or pictures on the interface of Roamer.

On a second visit, fifth-grade students engaged with Thymio. Students explored the functions that could be performed, again via trial-and-error, followed by explicit instruction from researchers. Students learned what the color functions of the Thymio meant, and soon learned that when Thymio turned: (a) green, he was in friendly mode and would follow an object like a hand placed in front of the sensors; (b) red, he was frightened and would back away from objects in front of sensors; and, (c) yellow, he was in explorer mode and would travel around the area, going around objects placed in front of it. Students assigned gender to the floorrobot, and often referred to the Roamer and the Thymio as male. Students learned how to have the Thymio follow black tape, follow other Thymios, and travel in circles.

On a third visit, student-participants interacted with the Roamer again. Students were asked to recall code from memory approximately one month after their introduction to the educational robot. Researchers asked students to: (a) recall and write down program code from memory in groups, (b) program Roamer to create geometric patterns in groups, and (c) write program code onto paper in a post-test individually. On a fourth visit, researchers developed a collaborative, small-group activity that included three structured lessons; and 


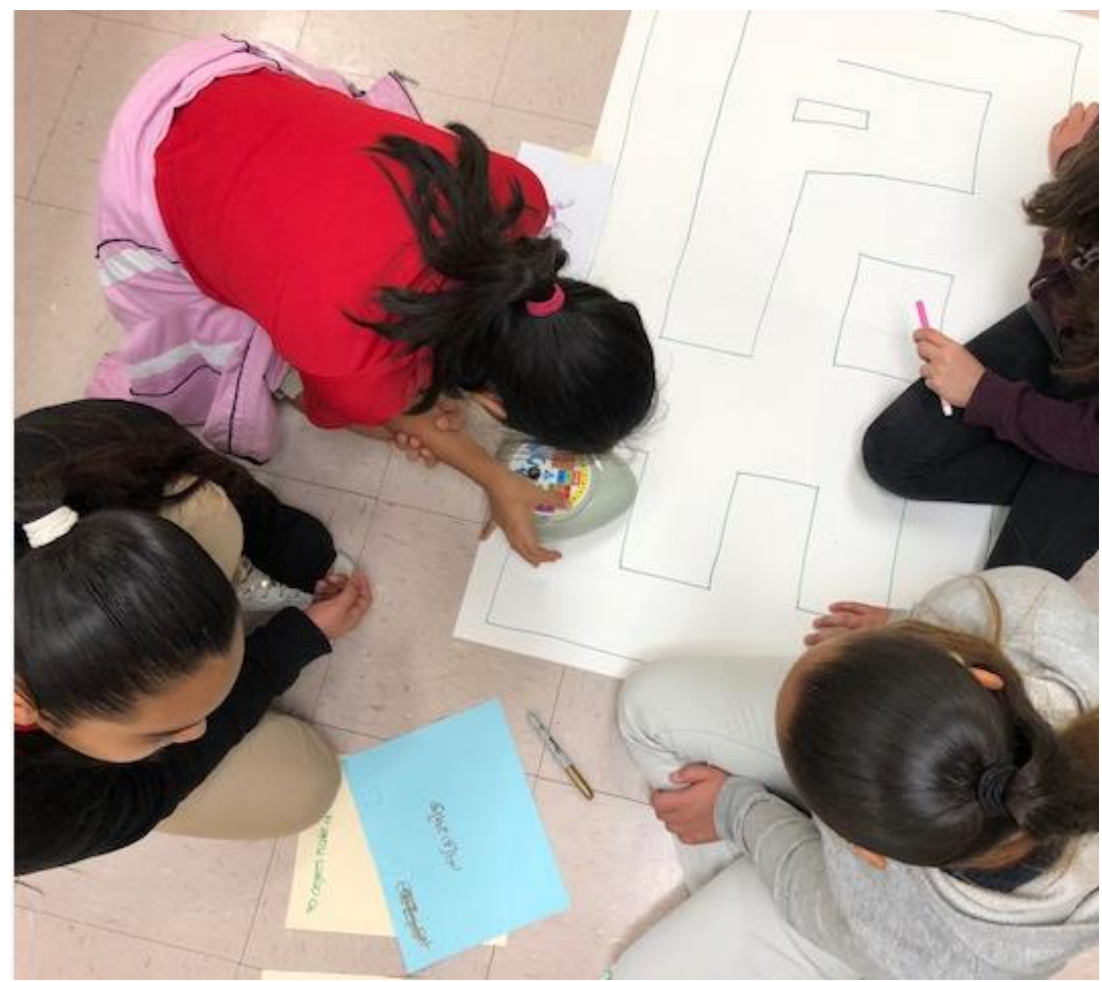

Figure 3. Working with Roamer at the Maze

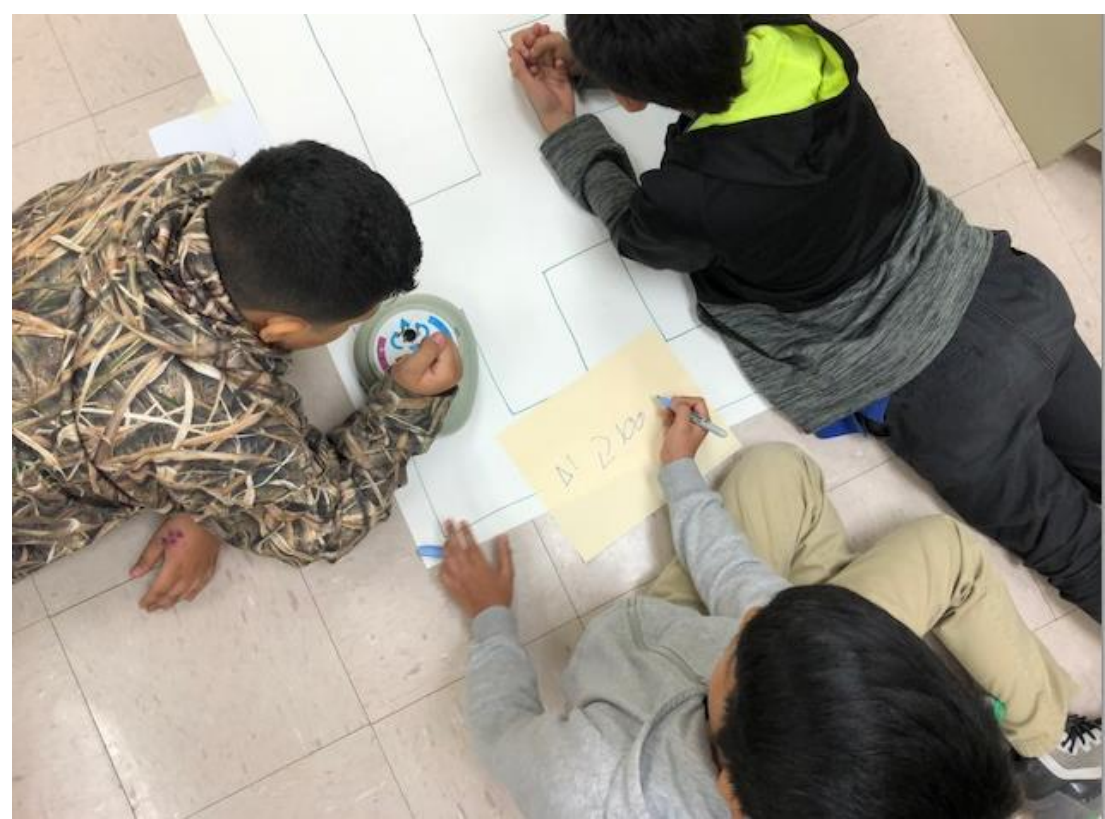

Figure 4. Writing code for Roamer

in groups of three to four, students were engaged with the floor-robots at different stations, moving between stations after twenty minutes. Data on this final engagement with floor-robots was gathered by researchers.

Station Teaching. During this culminating visit, fifth-grade student-participants interacted with both types of floor-robots. Students were placed in groups; and each group traveled through three stations, with structured activities developed by researchers. These activities included programming floor-robot(s) to travel in specific patterns or directions dependent upon floor-robot type. In total, there were seven stations, with three stations having a structured activity utilizing Roamer, two stations having a structured activity with two Thymio floor-robots, and two stations having another structured activity with one or two Thymios. At the three stations with Roamer (Figures 3-5), students had to program a floor-robot to travel through a maze. There were three openings to "exit" the maze, and each exit had a different Pokémon picture. 


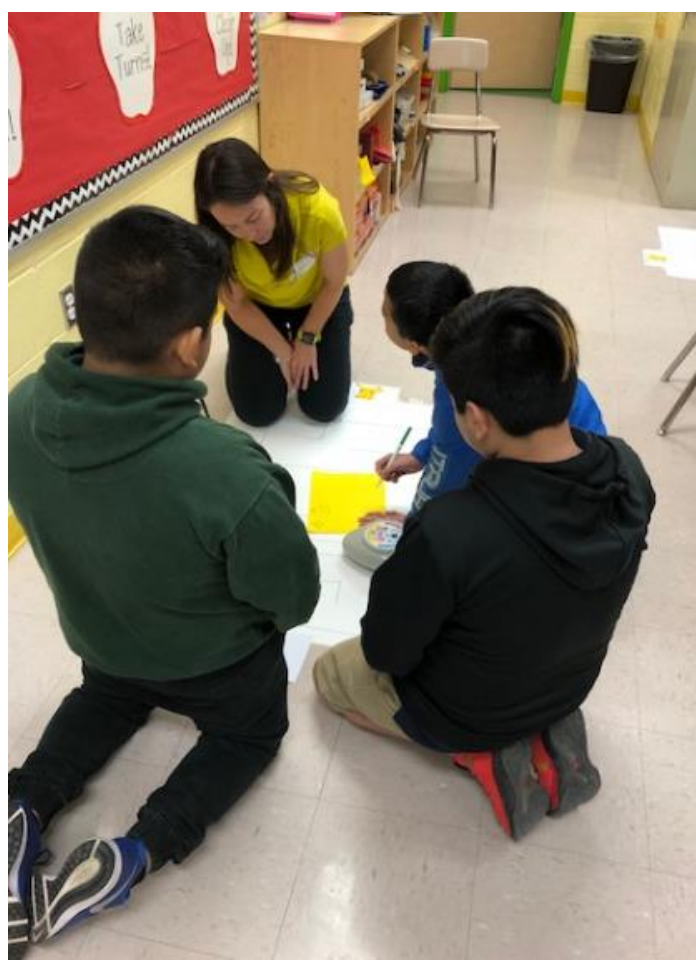

Figure 5. Assisting students

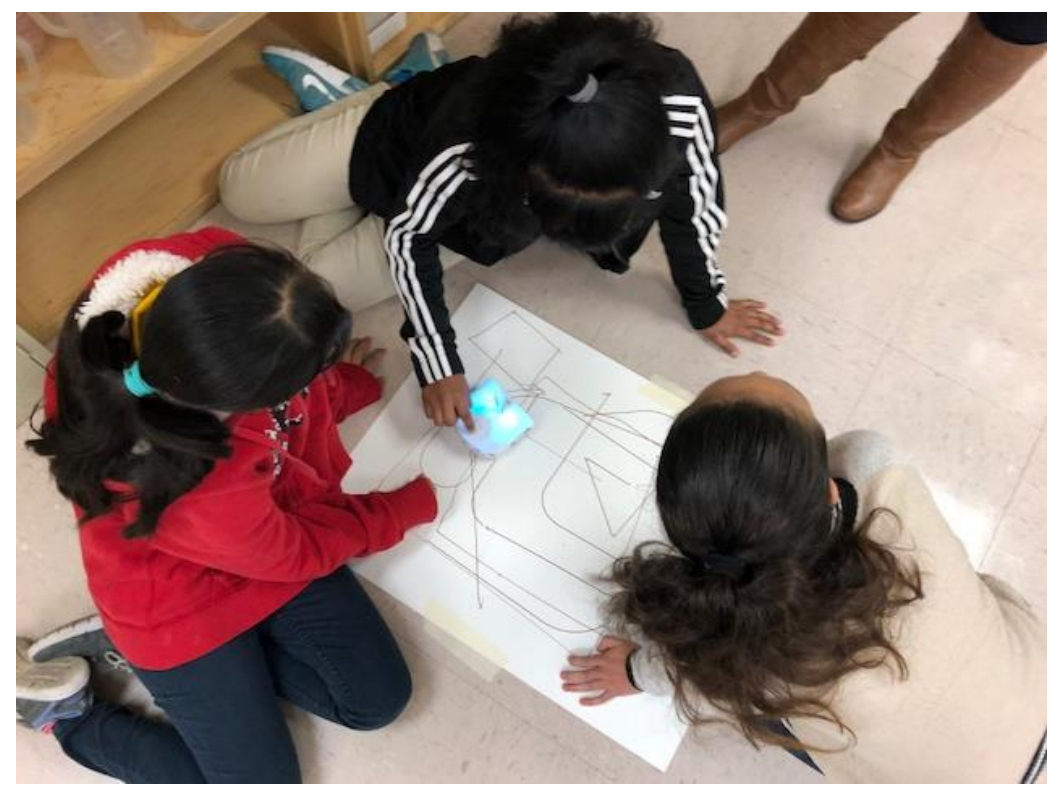

Figure 6. Working with Thymio

Students selected which exit they would program the floor-robot to travel toward; and students worked as a group, writing down code and analyzing the sequence of steps to ensure success.

Students had visual analysis of their attempts to program a path as they watched the floor-robot follow the code; and students intervened to stop the attempt if an error was seen. Although students worked diligently and were engaged, only two groups of students, out of four $5^{\text {th }}$ grade classes, successfully managed to program Roamer to exit the maze.

While working at the stations with the Thymio floor-robot, students were instructed to: (1) have the floorrobot travel in a circle to create three concentric rings, equidistant apart, and each consecutively larger; or, (2) create a path with markers and have two floor-robots traverse the path simultaneously, one following behind the other. The first task was challenging, and no students were able to complete the task, although all groups were trying diligently (Figures 6-9). 


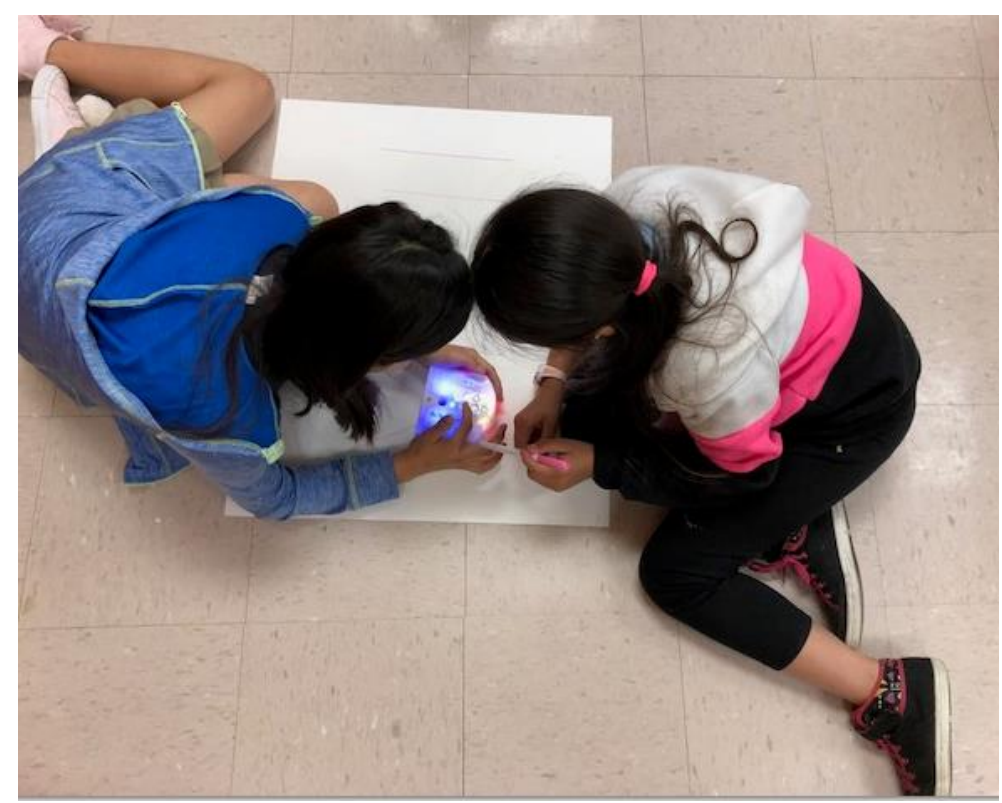

Figure 7. Programming Thymio to travel in circles

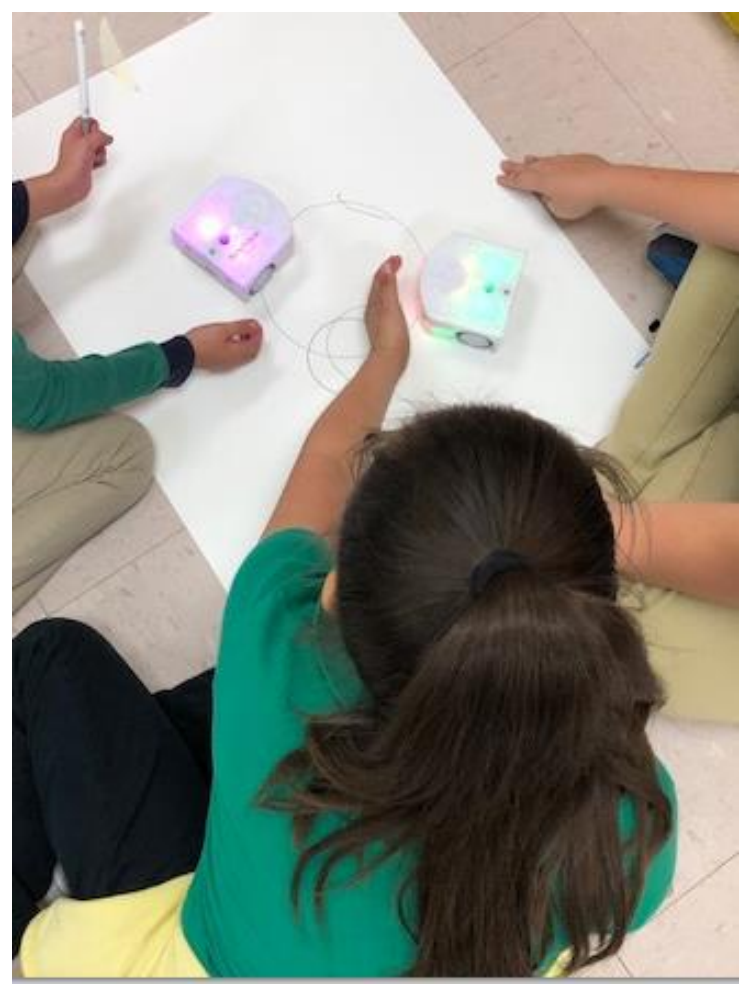

Figure 8. Working with multiple Thymio floor-robots

During this concluding lesson with floor-robots, there were four adults assisting students, including the cooperating teacher. The addition of three certified teachers and one graduate assistant limited any difficulty in managing behaviors; but, students remained engaged in groups. There was little to no off-task behavior observed by researchers. However, the researchers cannot determine if a single classroom teacher could effectively assist groups with a similar station lesson. Out of the seven stations, there were four adults readily available to assist. If this were a single classroom teacher, managing behavior and/or addressing students' questions may be more difficult. 


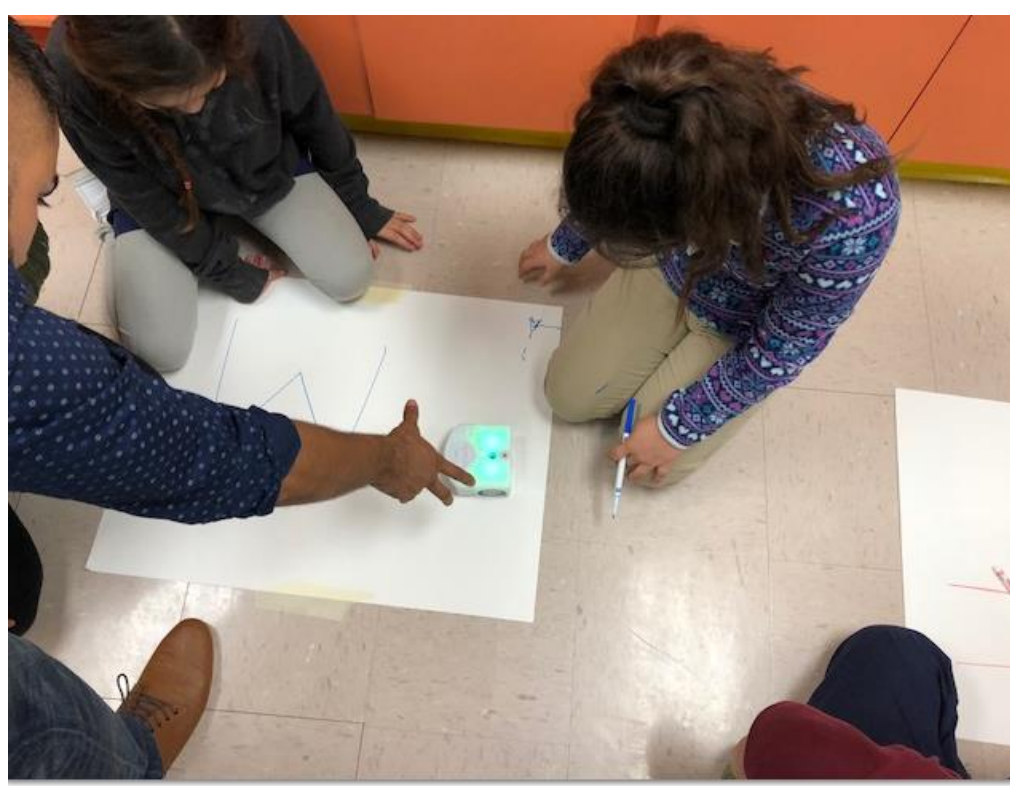

Figure 9. Assisting students

1. I am a
a. boy

b. girl

2. The floor robot I used in the maze was easy to program.

a. Yes

b. No

3. I want to be in a Robotics Club in Middle School

a. yes

b. no

|

4. I will go to college

a. No, I will not go

b. I am not sure

c. maybe

d. yes, I will definitely go

5. When I grow up, I want to have a career in science, math, engineering, or technology.
a. I do not think so
b. I am not sure
c. I think so
d. Certainly

6. Of these two robots, I like the

a. one that lights up

b. one that I put in the code

7. I would like my teacher to use floor-robots in class more often

$$
\text { a. Yes }
$$

b. No

8. I like to work in groups with other students

a. Yes

9. When I work with the floor-robot, I have to think about solving a problem.

a. Yes

b. No

Figure 10. Student questionnaire

\section{RESULTS}

After engaging in multiple activities involving floor-robots, student-participants responded to a researcherdesigned survey (Figure 10) to ascertain students' perceptions of floor-robots. Students responded to surveys 


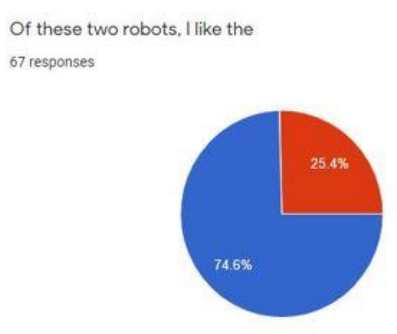

When I work with a floor-robot, I have to think about solving a problem. 67 responses

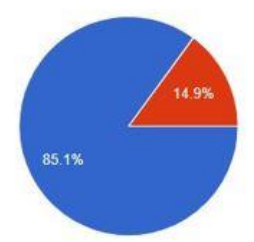

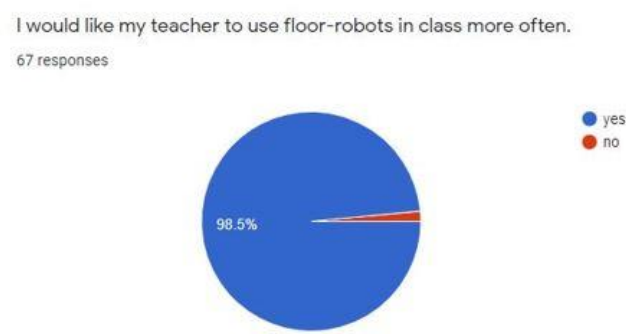

Of these two robots, Ilike the 67 responses

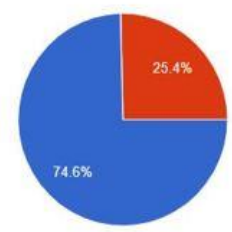
one that lights up (Thymio)

Figure 11. Results from questionnaire

after they had moved through all three stations and completed all activities. Responders were $61 \%$ female and $38.8 \%$ male. Researchers first wanted to identify if students found it difficult to program the Roamer floor-robot. Overwhelmingly, respondents found the robot easy to program. Likewise, students' responses revealed a positive interest in joining a robotics club and having teachers incorporate more floor-robots into instruction (Figure 11). As researchers did not collect data on students' interest in these two questions prior to initial data collection, it cannot be determined if floor-robots enhanced students' responses positively. However, most students were unaware of floor-robots prior to the start of this study. Nonetheless, it is important that elementary students receive formal and informal opportunities to engage in activities involving new technologies such as floor-robots, especially underserved students. On the question "I like to work in groups with other students", the overall response was strong (96.5\%). There were three students who responded that they did not enjoy working in groups. It is important to identify students who would prefer to work alone, particularly to identify areas of concerns students have and/or come up with solutions to ensure students' emotional needs are met. Along with this survey, researchers returned to the school and provided students with two open-ended questions approximately a month after the station lesson. The questions were: (a) If you could create a floor-robot, what would you want it to do? and, (b) What is your favorite thing about these robots? Students' responses to these statements were brief and minimal, with an average response between two to four words; and they were not coded. Nevertheless, researchers believed that these additional responses would provide further insight into students' perceptions of floor-robots. The principal investigator (PI) followed up with each student as they brought their papers to a designated area of the classroom.

On question one, many students wrote that they would create a floor-robot to "do my homework", "clean my room", and "do what I say". Some novel responses to question one included "talk", "make my things", "train my dog to respect me", "help the teacher", and "carry the teacher's books". On question two, students' responses varied. Some students referenced a specific floor-robot, and students wrote that they liked the floor-robot that: (a) "lit up", "made noises", "followed a hand", and "changed colors" (Thymio); and, (b) "had the coding games", and "made shapes and letters" (Roamer). These statements align with survey question six; and overwhelmingly, students preferred the Thymio over the Roamer floor-robot based on researchers' tally marks. Although students indicated that the floor-robots were easy to program, at times, the buttons on the Roamer floor-robot were difficult to push; and even though students thought that they had pushed all buttons correctly as they entered a code by selecting specific pictures on the interface, the floor-robot would not navigate successfully through the maze. Students found this frustrating, but this information is useful for teachers who may be trying to determine whether a floor-robot would be beneficial for students. 
Other responses to question two included that students liked that the floor-robots "moved on their own", "help you", "do more things", "it [sic] cool to use them", "do stuff for you", were fun to use", and "there [sic] helpful". One student liked the fact that Thymio's colors meant something; and, the student liked that Thymio "had feelings". As mentioned previously, when researchers initially introduced students to Thymio, students learned that the colors meant something; and when Thymio was: (a) red, he was scared and backed away from objects; (b) green, he was in friendly mode and followed a hand or another Thymio; (c) yellow, he was in explorer mode and would move around alone; and, (d) purple, he would travel in circles of various sizes. As stated earlier, students did assign gender to the floor-robots. Students were unable to access the coding software online tools for Thymio as the PI did not have access to school computers to download the software. However, students could push buttons on the floor-robot to change its color and make it travel in specific directions and/or basic patterns of various sizes.

Researchers have argued that educational robots may enhance students': (a) academic performance in STEM coursework (Toh et al., 2016); (b) creativity (Nemiro et al., 2017); (c) spatial thinking (Francis et al., 2017); (d) collaborative skills (Khanlari, 2016); and, (e) writing via Robot Theater (Kanda et al., 2007). Researchers in this study would argue that the use of continuing, structured activities with floor-robot increased studentparticipants' self-efficacy in technology. Although data on students' self-efficacy in working with floor-robots was not collected, researchers observed that students' comfort levels in working with Thymio and Roamer increased across this study. Students became more willing to program their own code and search for errors in code, rather than waiting for assistance from the $\mathrm{PI}$, the graduate student, or another researcher. With each succeeding visit with floor-robot activities, students worked harder to identify necessary code; and rather that giving up when their code was incorrect, they were more sure of their ability to correctly use the technology than in initial visits. Additionally, students requested that the researchers bring the floor-robots on subsequent visits.

\section{DISCUSSION}

Although students at this school continue to struggle with standardized, state assessments, the positive environment, energy, and willingness of student-participants to work hard was inspiring. All studentparticipants who engaged with the floor-robots were also involved in a larger study involving the effects of metacognitive strategy instruction on ELLs' academic performance in science. During the academic year, researchers introduced students to metacognitive strategies, collected multiple pre/post assessments and several surveys, and collected observational field notes while students were working with expository texts. The lessons with floor-robots required students to use some of the metacognitive strategies with floorrobots. Students were enthused and engaged in learning during instruction, but much more so when floorrobots were used.

The findings of this study align with other studies where floor-robots were introduced into elementary classrooms (Francis et al., 2017; Kanda et al., 2007; Khanlari, 2016; Nemiro et al., 2017; Toh et al., 2016). In studies in a review of the literature, student-participants were engaged in the learning environment and increased in some area of academic or behavioral performance. Student-participants in this study experienced an increased awareness of floor-robots; and through structured activities, students successfully used floor-robots, which reinforced their programming ability and self-efficacy in working with floor-robots. Researchers observing students did not see students prefer one floor-robot model over another; and when students moved between stations, no students were observed complaining about having to move to a center with a different robot model. Researchers inferred that students enjoyed working with floor-robots via direct observation. Likewise, on visits after students were initially introduced to floor-robots, students typically wanted to know if they would be working with floor-robots during subsequent visits.

\section{CONCLUSION, LIMITATIONS, AND RECOMMENDATIONS}

There were several limitations to the study. First, there were three certified classroom teachers present when students worked with floor-robots. As certified teachers, the researchers realize that this is not typical of a 
classroom setting. It would be useful to know if activities similar to the ones used in this study would run as smoothly with one classroom teacher present. Secondly, while students worked well in groups and were engaged, depending on class size, groups contained three or four students to one or two floor-robots. While all students participated and made suggestions for programming, in larger classes, students had limited time to actually program the robot individually, since that responsibility was shared. Researchers hope to acquire more floor robots to ensure group sizes are smaller in order to allow each student more time to enter program code into Roamer and Thymio. The Thymio floor-robot does not have specific pictures for students to select; rather, there are circles and triangles on Thymio that correspond to different functions depending on the color-mode of the robot.

Costs to purchase floor-robots must be considered another limitation, for researchers and classroom teachers alike. The typical cost of each model floor-robot used in this study was approximately 200 dollars. Thus, to acquire ten floor robots would be a substantial investment. Finally, additional training for a classroom teacher would allow him/her to run a similar activity at any time, and not just when researchers can be present. This would provide more frequent opportunities for students to engage with the floor robots. However, providing training is another added expense.

Researchers feel the study was beneficial in: (a) increasing students' awareness and use of floor-robots; and, (b) developing a better understanding of students' perceptions of floor robots. Further studies to determine if floor-robots increase students' self-efficacy in STEM would be beneficial. While previous tasks were connected to state mathematics' standards and provided students with a review, researchers believe that a wider variety of lesson plans and activities would allow students to work with robots throughout the year across multiple topics, thereby reinforcing skills at regular intervals.

Increasing students' awareness and use of new technologies such as educational robots is important, especially for female and minority students who are under-represented in STEM career areas (Mau \& Li, 2018; Seo et al., 2019). In this study, the use of floor-robots engaged students in critical-thinking and problem-solving, reinforced content and standards, and provided students with positive, collaborative experiences while working with peers. Making students aware of the possibilities within STEM career fields may provide motivation for students from underserved populations and provide them with a foundation to pursue those careers. Floor-robots used in the study were already available to researchers, and thus were convenient. In-service teachers might be encouraged to purchase one floor-robot with classroom funds, if available; teachers should receive assistance from a school technology expert in learning how to manipulate and use the technology. Further studies should focus on collecting data on: (a) a single teacher working with students engaged in activities with floor-robots, (b) students' STEM self-efficacy after engaging in activities with floor-robots, and, (c) studies that incorporate more styles/types of floor-robots.

\section{REFERENCES}

Bahnga, E., \& Lee, M. (2017). Learning experiences and practices of elementary teacher candidates on the use of emerging technology: A grounded theory approach. International Electronic Journal of Elementary Education, 10(2), 225-241. https://doi.org/10.26822/iejee.2017236118

Blackwell, E., \& Pinder, P. (2014). What are the motivational factors of first-generation minority college students who overcome their family histories to pursue higher education? College Student Journal, 48(1), 45-56.

Boden, K. (2011). Perceived academic preparedness of first-generation Latino college students. Journal of Hispanic Higher Education, 10(2), 96-106. https://doi.org/10.1177/1538192711402211

Boschma, J., \& Brownstein, R. (2016). The concentration of poverty in American schools. The Atlantic. Retrieved from https://www.theatlantic.com/education/archive/2016/02/concentration-povertyamerican-schools/471414/ 
Casey, J. E. (2018). The effects of reciprocal teaching on Latino students' awareness of comprehension strategies for expository text. Journal of the International Association of Special Education (JIASE), 18(1), 9-22.

Casey, J. E., Gill, P., Pennington, L., \& Mireles, S.V. (2018). Lines, roamers, and squares: Oh my! Enhancing Hispanic students' understanding and use of programming. Education and Information Technologies, 23(4), 1531-1546. Retrieved from https://link.springer.com/article/10.1007\%2Fs10639-017-9677-z

Conley, A. M., Pintrich, P. R., Vekiri, I., \& Harrison, D. (2004). Changes in epistemological beliefs in elementary science students. Contemporary Educational Psychology, 29, 186-204. https://doi.org/10.1016/j.cedpsych.2004.01.004

Engle, J., \& Tinto, V. (2008). Moving beyond access: College success for low-income, first-generation students. Washington, DC: The Pell Institute for the Study of Opportunity in Higher Education.

Ensign, T. I., Rye, J. A., \& Luna, M. J. (2017). Embedding probeware technology in the context of ocean acidification in elementary science methods courses. Journal of Science Education and Technology, 26(6), 646-656. https://doi.org/10.1007/s10956-017-9704-2

Francis, K., Bruce, C., Davis, B., Drefs, M., Hallowell, D. Hawes, Z., McGarvey, L., Moss, J., Mulligan, J., Okamoto, Y., Sinclair, N., Whiteley, W., \& Woolcott, G. (2017) Multidisciplinary perspectives on a video case of children designing and coding for robotics. Canadian Journal of Science, Mathematics and Technology Education, 17(3), 165-178. https://doi.org/10.1080/14926156.2017.1297510

Gamez-Vargas, J., \& Oliva, M. (2013). Adult guidance for college: Rethinking educational practice to foster socially-just college success for all. Journal of College Admission, 221, 60-68.

Hinkin, T. R. (1995). A review of scale development practices in the study of organization. Journal of Management, 21(5), 967-988. https://doi.org/10.1177/014920639502100509

Jeon, M., Fakhr Hosseini, M., Barnes, J., Duford, Z., Zhang, R., Ryan, J., \& Vasey, E. (2016). Making live theatre with multiple robots as actors: Bringing robots to rural schools to promote STEAM education for underserved students. The Eleventh ACM/IEEE International Conference on Human Robot Interaction. Association of Computing Machinery. https://doi.org/10.1109/HRI.2016.7451798

Kanda,T., Sato, R., Saiwaki, N., \& Ishigo, H. (2007). A two-month field trial in an elementary school for longterm human-robot interaction. IEEE Transactions on robotics, 23(5), 962-971. https://doi.org/10.1109/TRO.2007.904904

Khanlari, K. (2016) Teachers' perceptions of the benefits and the challenges of integrating educational robots into primary/elementary curricula. European Journal of Engineering Education, 41(3), 320-330. https://doi.org/10.1080/03043797.2015.1056106

Likert, R. (1932). A technique for the measurement of attitudes. Archives of Psychology, 140, 1-55.

Mau, W. C. J., \& Li, J. (2018). Factors influencing STEM career aspirations of underrepresented high school students. The Career Development Quarterly, 66(3), 246-258. https://doi.org/10.1002/cdq.12146

Nemiro, J., Larriva, C., and Jawaharlal, M. (2017). Developing creative behavior in elementary school students with robotics. The Journal of Creative Behavior, 51(1), 70-90. https://doi.org/10.1002/jocb.87

Perna, L. W. (2015). Improving college access and completion for low-income and first-generation students: The role of college access and success programs. Retrieved from http://repository.upenn.edu/gse_pubs/301

Sadler, P. M., Sonnert, G., Hazari, Z., \& Tai, R. (2012). Stability and volatility of STEM career interest in high school: A gender study. Science Education, 96(3), 411-427. https://doi.org/10.1002/sce.21007 
Seo, E., Shen, Y., \& Alfaro, E. C. (2019). Adolescents' beliefs about math ability and their relations to STEM career attainment: Joint consideration of race/ethnicity and gender. Journal of Youth and Adolescence, 48, 306-325. https://doi.org/10.1007/s10964-018-0911-9

Sparkman, L, Maulding, W. S., \& Roberts, J. G. (2012). Non-cognitive predictors of student success in college. College Student Journal, 46(3), 642-652.

Toh, L. P. E., Causo, A., Tzuo, P. W., Chen, I. M., \& Yeo, S. H. (2016). A review on the use of robots in education and young children. Educational Technology \& Society, 19(2), 148-163.

Yin, R. K. (2013). Case study research: Design and methods (5 $5^{\text {th }}$ ed.). Thousand Oaks, CA: SAGE Publications.

Correspondence: Jane Elizabeth Casey, Texas A\&M University Central Texas, USA. E-mail: j.casey@tamuct.edu 